\title{
Evaluation of Three Current Methods for the Determination of Creatine Kinase-MB Catalytic Activity
}

\author{
By J. Spincemaille, J. Delanghe, M. De Buyzere, M. Breemeersch and V. Blaton
}

Department of Clinical Chemistry, A.Z. Sint-Jan, Brugge, Belgium

(Received November 24, 1983/May 25, 1984)

Summary: Three current methods for the determination of the creatine kinase-MB activity were evaluated: electrophoresis (Beckman Inst.), ion-exchange MB-Zyme (J. T. Baker) and ion-exchange on aca (Du Pont).

Eighty patients were selected out of three groups: acute myocardial infarction, heart and vascular surgery patients and a number of noncardiac cases. The precision of the ion-exichange methods was comparable; CV $5.7 \%$ (aca) and CV 5.2\% (MB-Zyme) for a high creatine kinase-MB pool. Electrophoresis overestimated the creatine |kinase-MB lactivity and was less precise (CV 9.6\%) and less sensitive than the ion-exchange methods. The aca (Du Pont) method was less specific than the MB-Zyme. The main source of discrepancy was samples from certain patients in the surgery unit, which gave falsely high values by the aca method, and showed altered mobility in electrophoresis, suggesting an atypical creatine kinase. Three macro creatine kinase type I included in this study were erroneously determined as creatine kinase-MB by both the ion-exchange methods.

Vergleich von drei gebräuchlichen Methoden zur Bestimmung der katalytischen Aktivität von Kreatinkinase

Zusammenfassung: Drei Methoden zur Bestimmung der katalytischen Aktivität von Kreatinkinase-MB wurden vergleichend bewertet: die Elektrophorese (Beckman Instr.), das Ionenaustauschverfahren MBZyme (J. T. Baker) und das Ionenaustauschverfahren auf aca (Du Pont). Aus drei Gruppen wurden achtzig Patienten gewählt: Patienten mit akutem Myokardinfarkt, Herz- und Gefäßchirurgiepatienten und eine Anzahl von Patienten ohne Herzkrankheiten. Die Präzision der Ionenaustauschmethoden war vergleichbar: VK $5,7 \%$ (aca) und VK 5,2\% (MB-Zyme) für einen hohen Kreatinkinase-MB-Anteil. Die Elektrophorese ergab zu hohe Werte für Kreatinkinase-MB und sie war weniger präzise (VK 9,6\%) und weniger empfindlich als die ' Ionenaustauschmethode. Die aca-Methode (Du Pont) war weniger spezifisch als das Ionenaustauschverfahren MB-Zyme. Die wichtigste Quelle für Diskrepanzen waren Muster von einigen Patienten aus der chirurgischen Gruppe: für sie gab die aca-Methode zu hohe Werte, und die Elektrophorese zeigte eine veränderte Mobilität, was eine atypische Kreatinkinase suggerierte. Drei Makro-Kreatinkinasen (Typ I), welche in dieser Studie erwähṇt werdèn, wurden durch beide Ionenaustauschmethoden irrtümlicherweise als KreatinkinaseMB bestimmt.

\section{Introduction}

In the routine laboratory, creatine kinase (EC 2.7.3.2) isoenzyme $\mathrm{MB}(\mathrm{CK}-\mathrm{MB})^{1}$ can be assayed quantitatively by a number of techniques such as

1) Enzyme: Creatine kinase (CK, EC 2.7.3.2) (ATP: creatine Nphosphotransferase); CK-MM, creatine kinase muscle isoenzyme; CK-BB, creatine kinase brain isoenzyme; CK-MB, creatine kinase heart isoenzyme. ion-exchange chromatographic methods $(1-2)$ and electrophoresis (3). We compared the results of three of these methods: the Du Pont aca and J. T. Baker MB-Zyme ion-exchange chromatography, and the electrophoresis by Beckman Instr. Patients were carefully selected in order to obtain information on the specificity, sensitivity and efficiency (4) of these methods in the diagnosis of acute myocar- 
dial infarction classified according to the WHO diagnostic criteria (5) and confirmed by our Department of Cardiology. Random selection of patients does not provide enough representatives of different clinical cases, such as the relatively rare macro creatine kinase (IgG-bound creatine kinase) and atypical forms of creatine kinase (microheterogenity). The limitations of each method were investigated, by comparing the resulting data with those obtained from the combination of the other two or all three methods. Also the analytical precision data for the three methods were tested on two standards with low and high creatine kinase-MB obtained from a number of patients of the Department of Cardiology.

\section{Materials and Methods}

\section{Patients}

We collected eighty samples by venipuncture from eighty selected indoor patients.

Fifty were confirmed myocardial infarctions, three were known to have a persistent macro creatine kinase type I (IgG-bound creatine kinase) and twenty-seven had no proven myocardial infarction, from which a significant number $(n=15)$ came from the vascular surgery unit. Acute myocardial infarction patients' samples were collected between 12 and 24 hours after onset.

Procedures

Determinations of creatine kinase-MB catalytic activity were carried out immediately after centrifugation at $1200 \mathrm{~g}$ of the whole blood. If creatine kinase-MB could not be determined immediately, samples were frozen at $-25^{\circ} \mathrm{C}$, sometimes for several days. Total creatine kinase catalytic activity was determined by the modified method of Rosalki (6) on the aca system (Du Pont Instruments, Wilmington, DE 19898). The starting point was 0000 ., and the scale factor was 4892 . Creatine kinase-MB catalytic activity was also measured with the automated column chromatography Du Pont aca system. Quantitative isoenzyme electrophoresis was carried out on Paragon ${ }^{\mathrm{TM}} \mathrm{CK}$ (Beckman Instr., Inc. Brea, CA 92621) and scanned on a Microzone Densitometer (Beckman Inst. R-112, Iuc. Fullerton, CA 92634). The ion-exchange method MB-Zyme (J. T. Baker Chemicals B.V., Deventer, Holland) was used strictly according to the procedures of the manufacturer, on a UV-spectrophotometer (Beckman Instr., Inc. Iwine, CA 92713). Macro creatine kinases (IgG-bound creatine kinases) were determined by a precipitation technique with Protein-A-Sepharose CL-4B (Pharmacia Fine Chemicals AB, Uppsala, Sweden) (7). To confirm these forms, activation energy was calculated after measuring the enzyme catalytic activity at $25^{\circ} \mathrm{C}$ and $37^{\circ} \mathrm{C}$ (8).

\section{Results}

\section{Macro creatine kinases}

The three macro creatine kinases type I migrated with an altered mobility in creatine kinase electrophoresis (between the MM and MB isoenzymes), as reported by several other investigators (7). These findings were confirmed from the calculated activa- tion energies, using the Arrhenius equation, and measuring the reaction at two different temperatures. From catalytic activity measurements at $25^{\circ} \mathrm{C}$ and $37^{\circ} \mathrm{C}$, activation energies of $42-50 \mathrm{~kJ} / \mathrm{mol}$ were calculated. The nature of the macro forms was determined by binding these sera to Pfotein A-Sepharose CL-4B, which revealed the presence of enzyme-IgG complexes. Both the ion-exchange methods falsely indicated these macro creatine kinases as creatine kinase-MB. This phenomenon was however recognized by the abnormally high $(>15 \%)$ creatine kinase-MB catalytic activities for these samples, with normal total creatine kinase values. Even in pure heart tissue, the creatine kinase-MB fraction of total creatine kinase, does not reach $25 \%$, when measured with an ion-exchange method (9). Two of these patients suffered from angina pectoris, and the other patient had clear autoimmune deficiencies (lupus erythematosus disseminatus). We considered macro creatine kinase type I as a separate entity, which can be distinguished only by an electrophoretic method. We therefore excluded these results so that further statistical interpretations were performed on a group of 77 patients. Ambiguous results from electrophoresis were excluded by means of a control serum sample containing the fluorescent albumin fraction (10).

\section{Creatine kinase-MB as myocardial infarc-} tion index

To minimize the number of false positives and negatives in our laboratory in conjunction with the clinical diagnosis of acute myocardial infarction by our Department of Cardiology, we took the following decision levels: for the ion-exchange methods, acute myocardial infarction-positive when creatine kinase$\mathrm{MB}$ is at least $3 \%$ of total creatine kinase; for the electrophoresis when creatine kinase-MB is at least $10 \%$. The creatine kinase-MB distribution of our selected patient group is given in table 1.

Tab. 1. Percentage distribution of creatine kinase-MB in serum in a group of 80 patients.

\begin{tabular}{lrr}
\hline $\begin{array}{l}\text { Creatine kinase-MB } \\
(\mathrm{U} / \mathrm{l})\end{array}$ & $\mathrm{n}$ & $\%$ \\
\hline $0-10$ & 21 & 26 \\
$11-20$ & 14 & 18 \\
$21-30$ & 12 & 15 \\
$31-40$ & 12 & 15 \\
$41-50$ & 3 & 4 \\
$51-100$ & 9 & 11 \\
100 & 9 & 11 \\
\hline
\end{tabular}

a Data obtained as the arithmetical mean of both ion-exchange methods. 


\section{Precision data}

The three described methods were tested on creatine kinase patient sera $(n=77)$ and on two pools; one from a patient group with total creatine kinase catalytic activity concentration of less than $200 \mathrm{U} / 1$ (Pool 1 , low) and the other obtained from a group with more than $200 \mathrm{U} / \mathrm{A}$ (Pool 2, high).

Precision data with respect to those pools are summarized on table 2. Electrophoresis overestimated both the low and high activity pools. The ion-exchange methods showed an increased precision for the high activity measurements.

\section{Method correlations}

The correlation between the two ion-exchange methods was good, with a coefficient of correlation $\mathrm{r}=0.967$ (fig. 1).

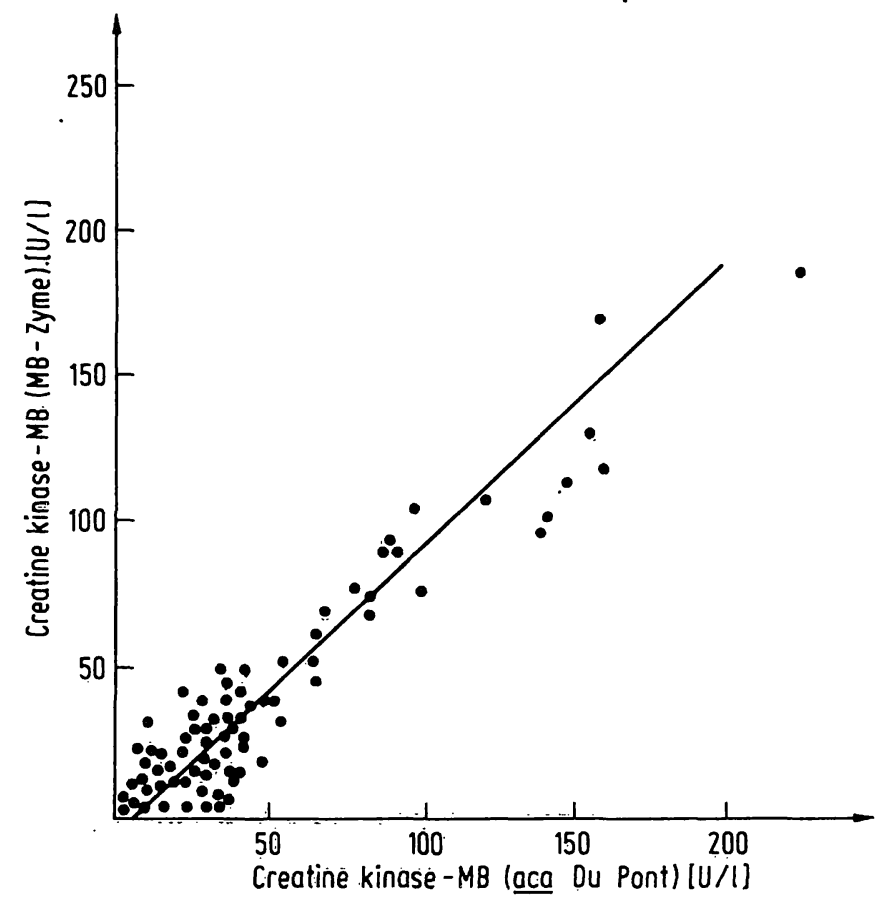

Fig. 1. Correlation of aca Du Pont and MB-Zyme creatine kinase-MB determination. $\mathrm{N}=77$; correlation coefficient $\mathrm{r}=0.967 ;$ regression line $\mathrm{y}=0.99 \mathrm{x}-3.45$.
This value was obtained when determinations were carried out immediately after thawing. In an experiment to study the influence of freezing on creatine kinase-MB catalytic activity we found that there was no significant decrease $(2.6 \%)$ in catalytic activity after freezing (Student t-test, $\mathrm{p}<0.01$, for all methods). The correlation between the ion-exchange methods and the electrophoresis was high ( $\mathrm{r}=$ 0.891 , mean value), as shown in figure 2 and fig-

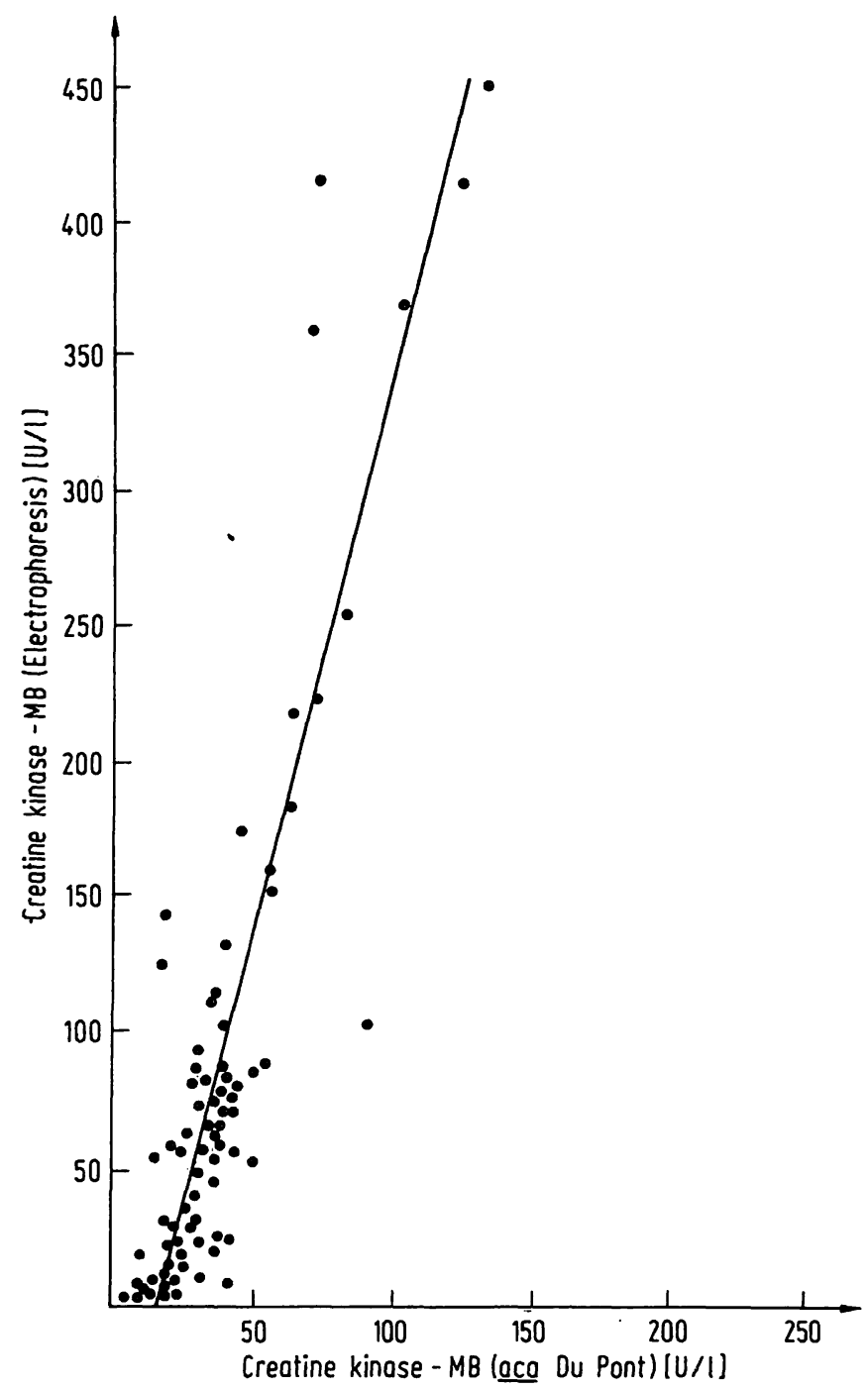

Fig. 2. Correlation of aca Du Pont and electrophoresis creatine kinase-MB determination. $\mathrm{N}=77$; correlation coefficient $r=0.893 ;$ regression line $y=3.49 x-15.93$.

Tab. 2. Comparison of precision data of three methods for measuring creatine kinase-MB catalytic activity concentration in human serum samples?.

\begin{tabular}{|c|c|c|c|c|c|c|}
\hline \multirow[b]{2}{*}{ Creatine kinase-MB standards } & \multicolumn{2}{|l|}{ aca Du Pont } & \multicolumn{2}{|l|}{ MB-Zyme } & \multicolumn{2}{|c|}{ Electrophoresis } \\
\hline & $\begin{array}{l}\text { Mean } \pm S D \\
(U / I)\end{array}$ & $\begin{array}{l}\text { CV } \\
(\%)\end{array}$ & $\begin{array}{l}\text { Mean } \pm S D \\
(U / 1)\end{array}$ & $\begin{array}{l}\text { CV } \\
(\%)\end{array}$ & $\begin{array}{l}\text { Mean } \pm S D \\
(U / I)\end{array}$ & $\begin{array}{l}\text { CV } \\
(\%)\end{array}$ \\
\hline $\begin{array}{l}\text { Pool 1b (low) } \\
\text { Pool 2c (high) }\end{array}$ & $\begin{array}{l}11.4 \pm 1.6 \\
30.4 \pm 5.7\end{array}$ & $\begin{array}{r}13.9 \\
5.7\end{array}$ & $\begin{array}{l}11.4 \pm 1.5 \\
30.3 \pm 1.6\end{array}$ & $\begin{array}{r}13.3 \\
5.2\end{array}$ & $\begin{array}{l}23.8 \pm 6.7 \\
89.0 \pm 8.5\end{array}$ & $\begin{array}{r}28.3 \\
9.6\end{array}$ \\
\hline
\end{tabular}

Based on tenfold analysis of each standard.

b Pool obtained from patients with total creatine kinase catalytic activity concentration less than $200 \mathrm{U} / \mathrm{l}$, as determined on aca Du Pont.

- Pool obtained from patients with total creatine kinase catalytic activity concentration greater than $200 \mathrm{U} / \mathrm{l}$, as determined on aca Du Pont. 


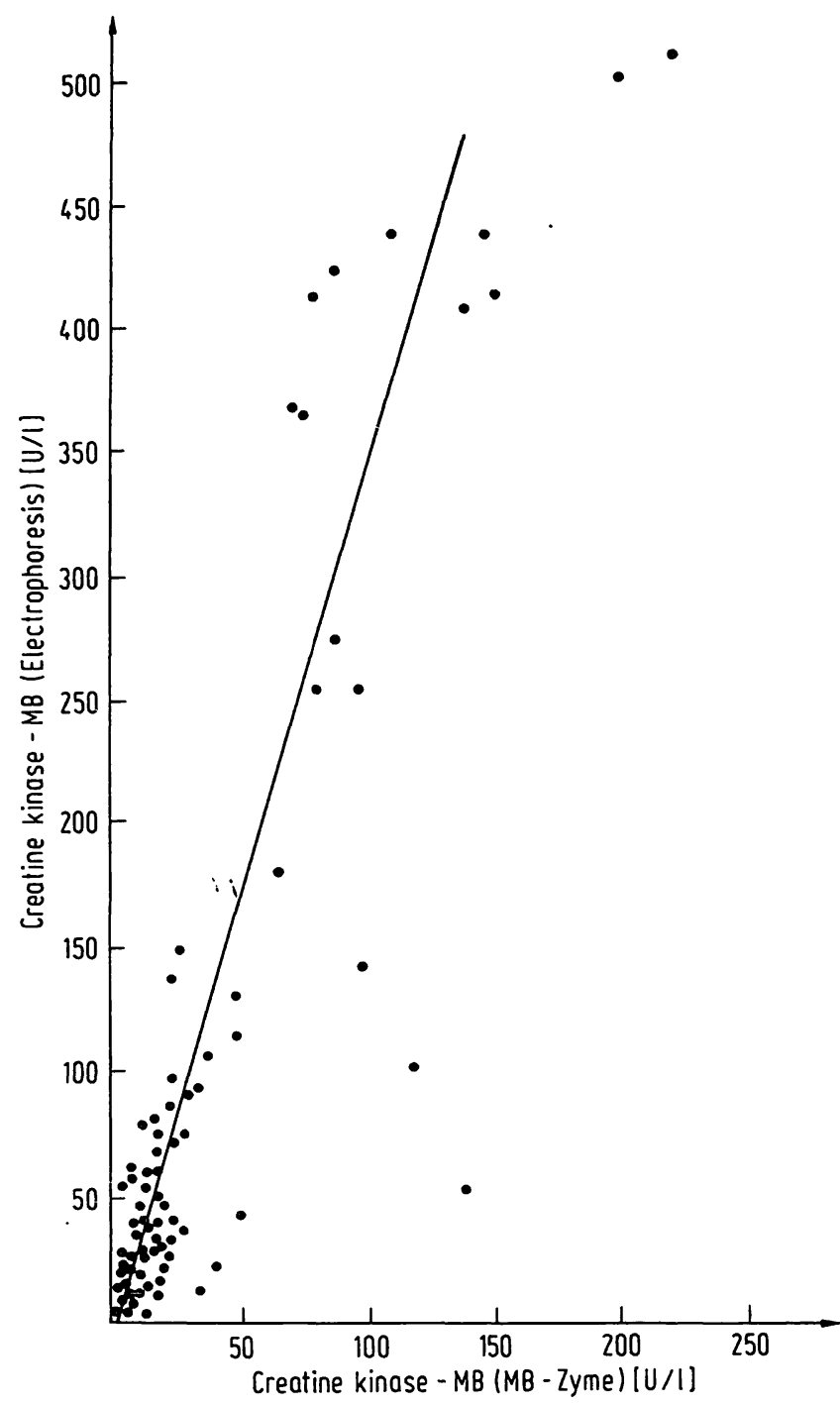

Fig. 3. Correlation of $M B-Z y m e$ and electrophoresis ${ }^{2}$ ) creatine kinase-MB determination. $\mathrm{N}=77$; correlation coefficient $r=0.889 ;$ regression line $y=3.34 x+1.00$. ure 3. Nevertheless the creatine kinase-MB was overestimated by electrophoresis, most probably due to a relative underestimation of the creatine kinaseMM fraction. The coefficient of correlation between Du Pont aca and electrophoresis was $r=0.891$ and between MB-Zyme and electrophoresis $\mathrm{r}=0.889$ with respective slopes of 3.49 and 3.34 .

\section{Reproducibility}

The aca-method showed a between-assay CV of $2.8 \%$ and the MB-Zyme assay showed a $\mathrm{CV}$ of $3.2 \%$, when the patient samples were measured in series on three executive days. Electrophoresis seemed to be less reproducible, with a between-assay CV of $10 \%$.

\section{Prediction data}

Each method sometimes gives a result that is in disagreement with those of the other two methods. In order to interpret these findings, all results were con= sidered in relation to the clinical diagnosis of acute myocardial infarction, independently by a team of cardiologists. Table 3 summarizes the true positives and true negatives when comparing a positive creatine kinase-MB value of one method with a clinical positive acute myocardial infarction diagnosis. With this information we calculated for each method the sensitivity, specificity, efficiency and the predictive values of a negative and a positive result as defined by Galen (4), table 3.

2) Percentage scanning units were formally transformed to activity units, in order to give a comparable statistical analysis for the three methods.

Tab. 3. Comparative prediction data of three methods for creatine kinase-MB in a group of 77 selected patients.

\begin{tabular}{|c|c|c|c|c|c|c|c|}
\hline Methods & $\begin{array}{l}\text { Falsely }{ }^{\mathrm{a}} \\
\text { negative }\end{array}$ & $\begin{array}{l}\text { Falselya } \\
\text { positive }\end{array}$ & Sensitivity ${ }^{b}$ & Specificityc & Efficiencyd & $\begin{array}{l}\text { Predictive }^{\mathrm{c}} \\
\text { value of } \\
\text { negative }\end{array}$ & $\begin{array}{l}\text { Predictive } \\
\text { value of } \\
\text { positive }\end{array}$ \\
\hline aca Du Pont & 1 & 7 & 98 & 74 & 88 & 95 & 88 \\
\hline MB-Zyme & 3 & 2 & 94 & 92 & 93 & 89 & $96^{\circ}$ \\
\hline Electrophoresis & 7 & 3 & 86 & 89 & 87 & 77 & 93 \\
\hline Creatine kinase total & 1 & 13 & 98 & 51 & 82 & 93 & 79 \\
\hline
\end{tabular}

a correlation was made to the confirmed diagnosis of acute myocardial infarction (A.M.I.) by our Department of Cardiology.

"Sensitivity $=\frac{\text { correctly classified A.M.I.'s }}{\text { total A.M.I.'s }} \times 100$

c Specificity $=\frac{\text { correctly classified non-A.M.I.'s }}{\text { total non-A.M.I.'s }} \times 100$

${ }^{d}$ Efficiency $=\frac{\text { true positives }+ \text { true negatives }}{\text { total patients }} \times 100$

- Predictive value of negative $=\frac{\text { true negatives }}{\text { total negatives }} \times 100$

$i$ Predictive value of positive $=\frac{\text { true positives }}{\text { total positives }} \times 100$

A.M.I. = Acute myocardial infarction 


\section{Discussion}

The clinical usefulness of the three methods is determined by their specificity, efficiency and sensitivity. As shown in figure 2 the Du Pont aca method gave for a number of patients $(n=4)$ higher values than expected. All were patients of the Department of Heart and Vascular Surgery and were operated upon the day before, but no incisions into the myocardium were made. Electrophoresis showed a slightly more anodic mobility than normal creatine kinase-MM. The same phenomenon was observed by Bayer et al. (11). In some patients suffering from myositis he found, in addition to the MB band, an additional band in the MM area.

In our study, this band sometimes passed through the aca column, and was consequently reported as falsely additional creatine kinase-MB. Perhaps this change is caused by incision of the skeletal muscles, but we did not observe this phenomenon in patients with multiple traumata. A few weeks after this study we saw a patient with hypothermia, showing the same additional band. Here we are dealing with creatine kinase-MM fractions bearing different surface charge, probably metastabile creatine kinaseMM (12) or fractions with a certain resemblance to mitochondrial creatine kinase as described by Leroux et al. (13). Within a population including such patients, the specificity of the aca Du Pont system is therefore decreased. However, vascular surgery patients are indeed a risk group for acute myocardial infarction. In such cases, attention must be paid to the interpretation of the aca creatine kinase-MB results, in order to avoid a false acute myocardial infarction diagnosis. The efficiency of the three methods is comparable. An excellent sensitivity is noted for the aca Du Pont system, while the Beckman electrophoresis showed a lower value due to the fact that very low creatine kinase-MB values could not be detected by this method. Also the predictive value of a negative was lower for the electrophoresis for the same reason. Electrophoresis is the best method for detecting macro creatine kinases; the ion-exchange methods failed to distinguish them. Macro creatine kinases appeared more often in patients with angina pectoris and in patients with autoimmune deficiencies, than in a normal population (14). This correlates well with the idea of Urdal (15) that macro creatine kinase type I can occur as a consequence of autoimmunity.

This study compared three current methods for measuring creatine kinase-MB in a group of selected patients. We studied the precision and prediction data of each method, as well as the predictive value for atypical creatine kinase-MB forms and macro creatine kinases.

Method correlations show that both ion-exchange methods are comparable, with an excellent sensitivity for the Du Pont aca method. In a selected patient group from the vascular surgery unit, this method reveals a low specificity. Electrophoresis is used with profit to investigate atypical forms and macro creatine kinases. Furthermore, care should be taken to avoid false diagnosis in the interpretation of creatine kinase-MB from patients suffering from angina pectoris or system deficiencies when determined with column chromatography.

It is preferable to determine total creatine kinase as well as measuring creatine kinase-MB by an ion-exchange method, in order to select abnormal isoenzyme patterns. Sera with aberrant creatine kinase$\mathrm{MB} /$ acute myocardial infarction ratios $(>0.10)$ are submitted to electrophoresis, in order to identify the nature of these multiple forms.

For follow-up purposes of acute myocardial infarction and vascular surgery patients, one has to pay attention to those high ratios. Some of them are not due to a recidivism of acute myocardial infarction, but to aberrant creatine kinase isoenzymes.

\section{References}

1. Mercer, D. W. (1974) Clin. Chem. 20, 36-40.

2. Morin, L. G. (1976) Clin. Chem. 22, 92-97.

3. Somer, H. \& Kontinnen, A. (1972) Clin. Chim. Ac̣ta 36, 531-536.

4. Galen, R. S. \& Gambino, S. R. (1976) In: Beyond Normality, p. 124. J. Wiley \& Sons, New York, NY.

5. WHO Working Groups, Evaluation of comprehensive rehabilitive and preventive programmes for patients after acute myocard infarction p. 26-30. WHO Regional Office for Europe (1972), Copenhagen.

6. Rosalki, S. B. (1967) J. Lab. Clin. Med. 69, 696-705.

7. Lang, H. \& Würzburg, U. (1982) Clin. Chem. 28, 14391447.

8. Stein, W., Bohmer, J., Steinhart, R. \& Eggstein, M. (1982) Clin. Chem. 28, 19-24.

9. Goulle, J. P., Merchard, D., Laine, G. \& Jeanmet, A. (1979) Ann. Biol. Clin. 37, 303-307.

10. Chi, D. J. (1979) Clin. Chem. 25, 494.

11. Bayer, P. M., Boehm, M., Hajdusich, P. \& Hotgchek, H. (1982) Clin. Chem. 28, 166-169.

12. Hamburger, H. A., Wold, L., Jacob, G. L. \& O'Brien, J. (1980) Clin. Chem. 26, 78-83.

13. Leroux, M., Jacobs, H. K., Rabkin, S. W. \& Desjardins, P. R. (1977) Clin. Chim. Acta 80, 253-254.

14. In preparation; Macro creatine kinase: prevalence and clinical significance.

15. Urdal, P. (1981) Scand. J. Clin. Lab. Invest. 4I, 499-505.

Dr. V. H. Blaton

Dept. Clinical Chemistry

A.Z. Sint-Jan

Ruddershove 10

B-8000 Brugge 
